\title{
Guidelines for clinical management of SARS-CoV-2 infection
}

\author{
José L. García-Álvarez* and José L. García-Vigil
}

Pharmacology Department, Faculty of Medicine, Universidad Nacional Autónoma de México, Mexico City, Mexico

\begin{abstract}
In SARS-CoV-2 infection (COVID-19), the most common manifestations involve the upper airways; in complicated cases, bilateral interstitial pneumonia, severe acute respiratory failure and multiple organ failure occur, which require hospital treatment and ventilatory support with nasal cannula or mask and high flow oxygen, or orotracheal intubation and mechanical ventilation. There are no specific antivirals, and thus management is symptomatic, as well as with antiplatelet drugs (acetylsalicylic acid, dipyridamole), low molecular weight heparin when there is hypercoagulability (increased D-dimer), dexamethasone when inflammation indicators are elevated; experimentally, under informed consent, antibiotics are used according to microbiological results, as well as interferon beta $1 \mathrm{~b}$, favipiravir, tocilizumab, ivermectin and immunoglobulin $\mathrm{G}$. When gastroenteritis occurs, nitazoxanide can be indicated.
\end{abstract}

KEY WORDS: SARS-CoV-2. COVID-19. Pneumonia. Favipiravir. Tocilizumab. Ivermectin. Immunoglobulin G. Nitazoxanide.

\section{Guía de manejo clínico del paciente con infección por SARS-CoV-2}

\section{Resumen}

En infección por SARS-CoV-2 (COVID-19), las manifestaciones más comunes son las de vías aéreas superiores; en casos complicados se presenta neumonía intersticial bilateral, insuficiencia respiratoria aguda grave y falla orgánica múltiple que ameritan tratamiento hospitalario y soporte ventilatorio por puntas nasales o mascarilla, así como oxígeno con flujo a presión alta o intubación orotraqueal y ventilación mecánica. No hay antivirales específicos por lo que el manejo es sintomático, así como con antiplaquetarios (ácido acetilsalicílico, dipiridamol), heparina de bajo peso molecular ante hipercoagulabilidad (dímero $D$ aumentado), dexametasona ante indicadores altos de inflamación. Previo consentimiento informado, experimentalmente se emplean antibióticos según los resultados microbiológicos, interferón beta $1 b$, favipiravir, tocilizumab, ivermectina e inmunoglobulina G. Cuando se presenta gastroenteritis se puede indicar nitazoxanida.

PALABRAS CLAVE: SARS-CoV-2. COVID-19. Neumonía. Favipiravir. Tocilizumab. Ivermectina. Inmunoglobulina G. Nitazoxanida.

\section{Introduction}

In humans, RNA viruses usually cause respiratory diseases, which range from common cold to the severe respiratory illness known as severe acute respiratory syndrome (SARS). SARS-CoV-2 is the RNA virus responsible for the current pandemic, which originated in Wuhan, China.

Human coronaviruses are transmitted by direct contact with secretions and through aerosol droplets. Infected patients also excrete the virus in feces and urine.
Correspondence:

*José L. García-Álvarez

E-mail: luismedint @yahoo.com
Date of reception: $23-05-2020$

Date of acceptance: 27-07-2020

DOI: 10.24875/GMM.M21000461
Gac Med Mex. 2020;156:576-583

Contents available at PubMed

www.gacetamedicademexico.com

0016-3813/@ 2020 Academia Nacional de Medicina de México, A.C.. Published by Permanyer. This is an open access article under the CC BY-NC-ND license (http://creativecommons.org/licenses/by-nc-nd/4.0/). 
The parts that make up the general structure of coronaviruses are, as in all animal viruses, the envelope and the nucleocapsid. The coronavirus envelope contains a 20- to 35-kDa membrane (M) glycoprotein, which forms a matrix that is in contact with the nucleocapsid. The envelope also contains the $180-220-\mathrm{kDa}$ $\mathrm{S}$ glycoprotein, which forms the spicules, i.e., the spikes responsible for adhesion to the host cell. In the specific case of SARS-CoV-2 spicules, a binding domain for defined receptors directs virus adherence to its cell receptor, angiotensin-converting enzyme 2 (Fig. 1).

\section{Pathophysiology}

Rapidly-deteriorating COVID-19 patients present with laboratory and clinical data consistent with macrophage activation syndrome, the pathophysiology of which shows the following:

- T-cells uncontrolled proliferation.

- Macrophages excessive activation.

- Hypersecretion of pro-inflammatory cytokines, interleukins (IL) $1 \beta$ and 6 , interferon, and tumor necrosis factor $\alpha{ }^{1}$

In the pathophysiological process, an effect of viral binding to hemoglobin heme group has been found. Hemoglobin binding with coronavirus decreases oxygen transport capacity; therefore, cellular hypoxia with increased anaerobic metabolism and early multiple organ damage is generated. ${ }^{2}$ Viral binding appears to have higher affinity for glycated hemoglobin, a situation that explains why diabetic patients have an increased risk of progressing to serious disease. Among the laboratory parameters, hyperferritinemia constitutes the best indicator of exaggerated immune response. ${ }^{3}$

Thrombin pathological activation is identified in patients with rapidly-deteriorating COVID-19, with multiple thrombotic episodes that range from peripheral ischemia and pulmonary thromboembolism to disseminated intravascular coagulation being observed. The most appropriate laboratory parameter to recognize this thrombophilic state is elevated D-dimer.

\section{Operational definitions}

- Suspected case. Person of any age who has had at least two of the following signs and symptoms within the last seven days: fever, cough or headache, accompanied by at least one of the following signs and symptoms: ${ }^{4}$

- Dyspnea (indicative of severity)
- Arthralgia

- Myalgia

- Odynophagia/pharyngeal burning

- Rhinorrhea

- Conjunctivitis

- Chest pain

- Confirmed case. Person who meets the operational definition of suspected case and has a laboratory-confirmed diagnosis issued by the Institute for Epidemiological Diagnosis and Reference. ${ }^{5}$

\section{Initial evaluation and considerations at hospital admission}

Clinical judgment should prevail in the evaluation of the COVID-19 patient admitted to the hospital. Patients may present with mild, moderate or severe clinical features, including pneumonia, acute respiratory distress syndrome (ARDS), sepsis, and septic shock. Suspicion of severe pneumonia will be established immediately during initial evaluation if there is presence of respiratory failure (oxygen saturation [SaO2] $<90 \%$ while breathing ambient air), tachypnea and increased work of breathing. If it is an uncomplicated disease, care at home can be considered, with clear instructions regarding early identification of alarm signs for going to the the hospital for evaluation.

\section{Clinical data related to SARS-CoV-2 infection}

Usually, the incubation period ranges from four to six days, although it can be as long as 14 days. Symptoms are cough in 65 to $80 \%$ of cases, fever at admission in $45 \%$ and during the course of the disease in $85 \%$, dyspnea in 20 to $40 \%$, upper respiratory tract infection symptoms in $15 \%$, and gastrointestinal symptoms in $15 \%$. Most cases occur in adults, according to the series reported in China. Pediatric cases are rare, although clinical data with a predominance of abdominal pain, diarrhea and vasculitis similar to that observed in Kawasaki disease have been described in this age group.

\section{Laboratory and imaging investigations}

- Blood count with leukopenia and lymphopenia in $80 \%$ of cases.

- Kidney function tests, which show an increase in blood urea nitrogen/creatinine ratio. 


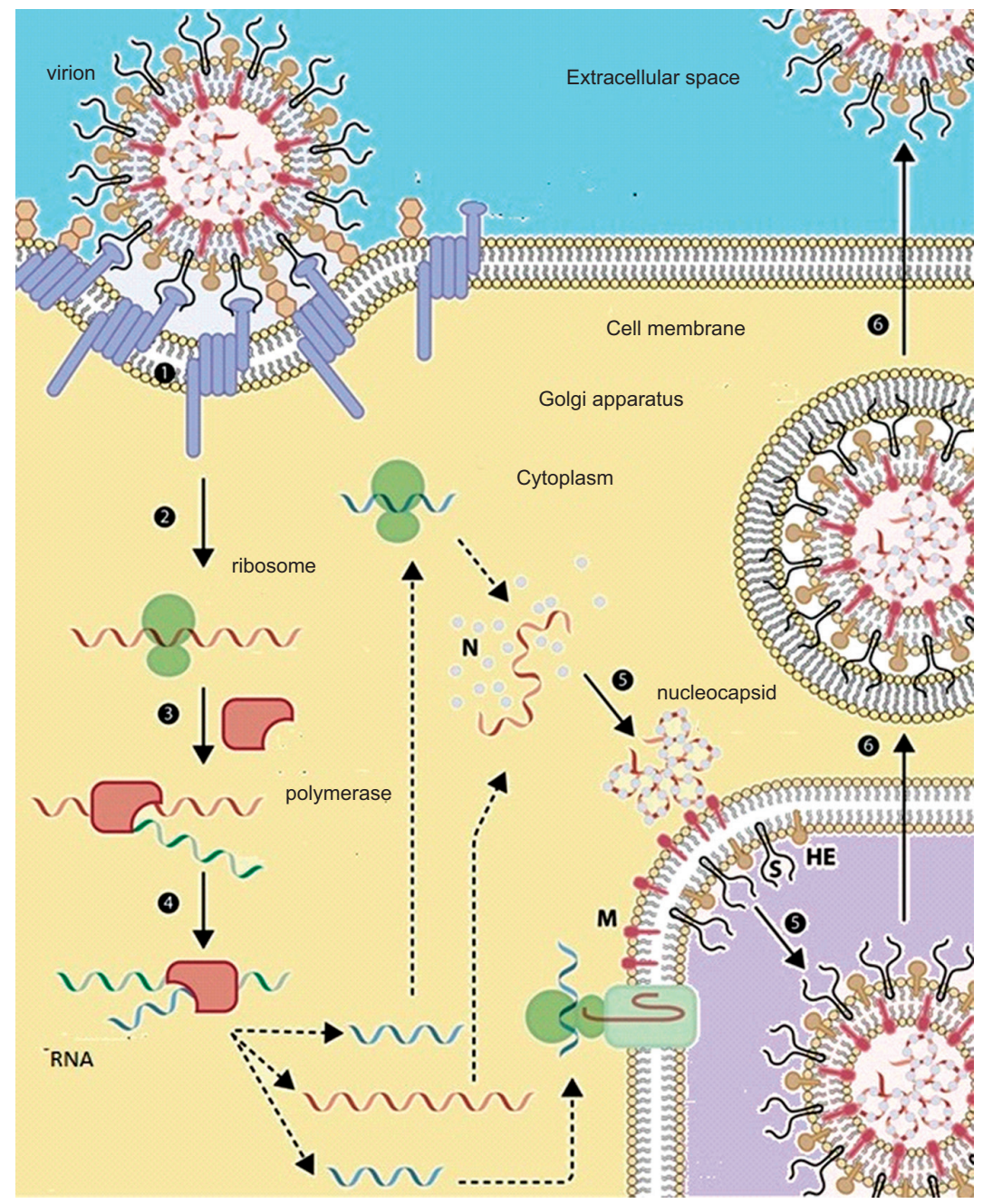

Figure 1. SARS-CoV- 2 replication cycle.

- Liver parameters with increased aspartate aminotransferase, alanine aminotransferase and total bilirubin.

- Positive D-dimer, positive polymerase chain reaction (PCR), and increased lactate dehydrogenase as a marker of tissue damage.

- Normal procalcitonin, but increased in cases of bacterial superinfection.

- Ferritin and IL-6 elevated levels.

\section{Imaging studies}

Chest X-ray is normal in patients with mild or moderate disease, but, in some cases, interstitial infiltrate and ground-glass opacity images are observed. In patients with severe COVID-19 and associated pneumonia, bilateral multi-segmental infiltrates are seen.
On chest tomography, presence of bilateral infiltrates and ground-glass opacity images can be observed earlier.

\section{Microbiological diagnosis and complementary tests}

- Rapid influenza diagnostic test.

- Respiratory viral panel to rule out respiratory syncytial virus, adenovirus, type 1, 2 and 3 parainfluenza and influenza $A$ and $B$ viruses.

- Bacterial polycultures as appropriate.

- Polymerase chain reaction (PCR) for SARS-CoV-2.

If the criteria for COVID-19 case are met, nasopharyngeal and oropharyngeal swab specimen collection is necessary. 
Serum determination of $\lg G$ and $\lg M$ antibodies against COVID-19 is of little use in the early phase, since it is positive only after day $7 .^{6}$

\section{Treatment}

Currently, there is no evidence from controlled clinical trials to recommend a specific treatment in patients with suspected or confirmed COVID-19, in whom general measures, fluid therapy with crystalloids and temperature control with conventional oral or preferably intravenous paracetamol are indicated. Routine use of non-steroidal anti-inflammatory drugs ${ }^{7}$ or systemic corticosteroids is not recommended, but their use can be contemplated in cases of acute respiratory distress syndrome, septic shock, encephalitis, hemophagocytic syndrome and when there is frank bronchospasm with wheezing. Low molecular weight heparin is recommended as antithrombotic prophylaxis.

\section{Respiratory therapy}

Oxygen therapy is started with $\mathrm{SaO}_{2}<92 \%$ while breathing ambient air, with the purpose to maintain values above $90 \%$, preferably with conventional devices using nasal cannulas. Patients already receiving oxygen therapy may develop acute respiratory distress syndrome. As an initial step, masks with reservoir bag shall be used, trying to maintain minimum flows of 10 to $15 \mathrm{~L} /$ minute and an inspired fraction of oxygen between 0.60 and 0.95 .

High-flow oxygen cannulas or non-invasive mechanical ventilation should be reserved for specific patients. Non-invasive mechanical ventilation should in no case delay the indication for intubation. Up to $70 \mathrm{~L} /$ minute of high-flow oxygen can be supplied, which is a measure that, compared to conventional oxygen therapy, reduces the need for intubation; it is not recommended in patients with hypercapnia, hemodynamic instability or multiple organ failure.

If invasive mechanical ventilation is necessary, intubation shall be performed by expert personnel, with the precautionary measures to avoid airborne virus transmission.

Treatment with drug micro-nebulizations is not recommended owing to the possibility of generating aerosols that increase the potential for viral transmission. In case of bronchial spasm, the use of individual pressurized devices in conjunction with a spacer chamber is recommended.
Antibiotics are not initially recommended, although they could be indicated based on clinical findings, blood test results or microbiological results. ${ }^{8}$

Oseltamivir is a neuroaminidase inhibitor drug that is used in influenza-positive cases and in patients with acute respiratory syndrome of uncertain etiology or with no specific results.

\section{Specific antiviral treatment}

So far, there is no specific antiviral treatment, and the use of the following should therefore be considered, after informed consent is granted by the patient:

- Hydroxychloroquine. Antimalarial drug in $200 \mathrm{mg}$ tablets, widely used in rheumatologic diseases. Its antiviral effect is attributed to macrophage lysosomes stabilization, phagolysosomes activation and alkalinization, inhibition of viral replication, and IL-6 and tumor necrosis factor release suppression. Initial dose is $400 \mathrm{mg}$ every 12 hours on the first day and then $400 \mathrm{mg}$ daily for seven days in mild and moderate cases, with an extension to 14 days in patients with severe pneumonia.

- Chloroquine. Available in $150 \mathrm{mg}$ tablets. The dose is $300 \mathrm{mg}$ every 12 hours on the first day and then $300 \mathrm{mg}$ every 24 hours. As side effects, maculopathy and QT-segment prolongation on electrocardiogram have been recorded. Although the efficacy of this drug in COVID-19 is unknown, several case series in China and Europe have demonstrated negativization of viremia at seven days.

In recent series, no benefits have been recorded with the use of hydroxychloroquine and chloroquine, and an increase in mortality due to cardiac arrhythmias has even been observed, with complete phase I to III studies being therefore required to determine pharmacological efficacy and safety.

- Lopinavir/ritonavir. Protease inhibitor available in 200/50 mg tablets. Dosage: two tablets every 12 hours for seven to 10 days, which in patients with moderate disease or severe pneumonia can be prolonged to up to 14 days. Diarrhea, nausea, and vomiting have been reported as common adverse effects; as uncommon, pancreatitis and QT-segment prolongation on electrocardiogram. Efficacy of this drug was not demonstrated in a case series published in 2020 by the New England Journal of Medicine. ${ }^{9,10}$ 
- Remdesivir. Viral RNA polymerase inhibitor that reduces viral replication. The suggested loading dose on the first day is $200 \mathrm{mg}$ intravenously, with maintenance doses of $100 \mathrm{mg} /$ day intravenously on days 2 to 10 . Infusion-related hypotension is the main adverse effect and precautionary indication. Moderate efficacy of this drug was observed in a trial approved in April 2020 by the United States Food and Drug Administration for emergency use in COVID-19. ${ }^{11}$

- Interferon beta-1b. Inhibitor of a broad spectrum of genes that limit the synthesis of RNA-activated protein kinase- $R$ and of 2'-5' oligoadenylate synthetase; it activates the MxA protein and limits viral replication. Indicated dose in severe pneumonia is $0.25 \mathrm{mg}$ subcutaneously every 48 hours for 10 to 14 days. Main adverse effects and precautionary indications are fever, headache, hypertonia, myasthenia, rash, nausea, diarrhea, lymphopenia, leukopenia, local reaction, weakness, arthralgia, and flu-like syndrome. Efficacy of this drug in the treatment of COVID-19 is unknown.

- Favipiravir. RNA polymerase-dependent viral RNA inhibitor that causes peptide chain termination and prevents viral RNA elongation. It prevents the formation of viral proteins that favor hemoglobin heme group attack. The recommended dose is 2400 to $3000 \mathrm{mg}$ every 12 hours on the first day, followed by $1200-1800$ mg every 12 hours. Favipiravir is available only in Japan, and its distribution is thus far not viable in America and Europe.

- Tocilizumab. Monoclonal antibody that inhibits IL- 6 action and that is used for the treatment of cytokine-release syndrome. In small series of 21 patients, improvement was observed in $91 \%$ of cases with administration of $400 \mathrm{mg}^{12,13}$

If specific antiviral therapy and adjuvant antimicrobial therapy are necessary, care should be taken not to combine chloroquine and lopinavir/ritonavir with macrolides or quinolones, due to the risk of QT-segment prolongation on electrocardiogram. Consideration should be given to the use of beta-lactam antibiotics in patients allergic to penicillin and carbapenems (Table 1).

\section{Treatment proposals}

With the understanding of the pathophysiological processes involved in COVID-19, it is possible to propose pharmacological treatments aimed at blocking strategic aspects.
The use of chloroquine and hydroxychloroquine is propose, since these drugs promote the modification of cell $\mathrm{pH}$ and reduce the possibility of the viral endocytosis process and binding of viral proteins to the heme group and, therefore, reduce the release of iron and the possibility of cellular hypoxia; in addition, their immunomodulating effects reduce the possibility of progression to cytokine-release syndrome.

Immunomodulatory drugs, such as colchicine and pirfenidone, could also be used, with the purpose to reduce the risk for the development of cytokine-release syndrome and, secondarily, the possibility of progression to pulmonary fibrosis in patients with already-established pneumonia.

Corticosteroids should be rationally used, since they decrease viral clearance by inhibiting an adequate immune process. In short cycles of five to 10 days, corticosteroids can favor recovery, especially when viral replication has been controlled, confirmed by a progressive reduction of ultrasensitive $\mathrm{C}$-reactive protein, which is usually observed after day 5 of having started specific antiviral treatment. 0.5 to $1 \mathrm{mg} / \mathrm{kg} /$ day of methylprednisolone or $6 \mathrm{mg} /$ day of dexamethasone or their prednisone and deflazacort equivalents are recommended.

Drugs that reduce exaggerated immune response by blocking the Jak/Stat pathway (baricitinib or ruxolitinib), an intracellular pathway that is directly involved in the transduction of information generated by various cytokines and that controls immune and inflammatory responses, can be used.

There are various investigational medicinal products, such as nitaxozanide, an agent designed for the treatment of predominantly parasitic gastrointestinal infections, whereby in vitro activity against SARSCoV-2 and MERS-CoV has been observed by inhibiting their proliferation and possessing immunomodulatory capacity. Prospective studies are required in order to evaluate nitaxozanide efficacy in clinical practice, since it is a highly available drug.

Camostat mesylate is a drug approved in Japan for the treatment of pancreatitis. In vitro, it prevents intracellular incorporation of SARS-CoV-2 by inhibiting serine protease; in the future, it promises to be a suitable drug for the treatment of SARS-CoV-2 infection.

Regarding the treatment with immunoglobulin, as in the protocols against influenza A (H1N1) in 2009, anecdotal series showed an adequate response with administration of plasma from SARS-and MERS-recovered patients. Its administration is recommended within the first seven to 10 days of disease onset, since, at that 
Table 1. Diagnostic criteria and treatment recommendations

Clinical scenario
Severe pneumonia in a patient with suspected or confirmed
COVID-19. Includes pneumonia plus any of the following.
- Respiratory rate $>30 /$ minute
- Oxygen saturation $<90 \%$ with inspired fraction of oxygen at

$21 \%$
- Assisted mechanical ventilation requirement
- Impaired alertness
- Hemodynamic instability and vasoactive amines requirement
- CURB-65 (scale for predicting mortality in patients with
community-acquired pneumonia) score $>2$ points
- Increase in pulmonary infiltrates by more than $50 \%$ between

24 and 48 hours
- Special care unit stay requirement

Pneumonia without severity criteria in a patient with suspected or confirmed COVID-19 with any of the following conditions.

- Age > 60 years

- Diabetes mellitus

- Cardiovascular disease

- Chronic obstructive pulmonary disease

- Chronic kidney disease

- Lung structural pathologies

- Immunocompromise

Deliberate search for data consistent with immunothrombotic response

Pneumonia without severity criteria and without comorbidities

Mild forms with comorbidities

Normal chest X-ray

Mild forms without comorbidities and normal chest X-ray

\section{Recommendation}

1. Supportive care

2. Ivermectin

3. Hydroxychloroquine or chloroquine $400 \mathrm{mg}$ or $300 \mathrm{mg}$ every 12 hours on the first day and continue with $400 \mathrm{mg}$ or 300 every 24 hours for seven days, considering extending to $10-14$ days $+$

4. Lopinavir/ritonavir $200 / 50 \mathrm{mg}$. Two tablets every 12 hours for seven to 10 days

or

5. Remdesivir $200 \mathrm{mg}$ initial dose and continue with $100 \mathrm{mg}$ intravenously every 24 hours for 10 days, considering extending the period to 14 days if necessary

6. Usual antimicrobial treatment for pneumonia and according to culture results

7. Low molecular weight heparin. Enoxaparin $1 \mathrm{mg} / \mathrm{kg}$ every 12 hours

8. Corticosteroids. Methylprednisolone or dexamethasone, short cycle, up to 10 days

9. Tocilizumab $8 \mathrm{mg} / \mathrm{kg}$

1. Supportive care

2. Ivermectin

3. Hydroxychloroquine or chloroquine $400 \mathrm{mg}$ or $300 \mathrm{mg}$ every 12 hours on the first day and continue with $400 \mathrm{mg}$ or $300 \mathrm{mg}$ every 24 hours for seven days considering extension to 10 days or

4. Lopinavir-ritonavir $200 / 50 \mathrm{mg}$. 2 tablets every 12 hours for seven to 10 days

5. Low molecular weight heparin

Enoxaparin $1 \mathrm{mg} / \mathrm{kg}$ every 12 hours

6. Usual antimicrobial treatment for pneumonia

7. Corticosteroids. Methylprednisolone or dexamethasone short cycle, up to 10 days

1. Symptomatic treatment (paracetamol)

2. Usual antimicrobial treatment for pneumonia

3. Ivermectin

1. Symptomatic treatment (paracetamol)

2. Usual antimicrobial treatment (levofloxacin, azithromycin, or clarithromycin)

3. Ivermectin

1. Symptomatic treatment (paracetamol)

2. Consider usual antimicrobial treatment (amoxicillin clavulanate) in case of data consistent with bacterial infection

3. Ivermectin time, viral replication is at its peak and host immune response has not developed at that time.

Ivermectin is an anti-parasitic agent approved by the Food and Drug Administration that has demonstrated antiviral activity against a wide range of viruses in vitro. The mechanism of action lies in inhibiting nuclear import of viral proteins to the host. Ivermectin is active against RNA viruses by inhibiting the interaction of a protein called IMP a/B1.

In recent in vitro studies, ivermectin was used in cultures of cells infected with SARS-CoV-2, with the presence of viral RNA being determined by reverse transcriptase PCR (RT-PCR). A reduction in viral load was demonstrated 48 hours after administration of the drug, with a $93 \%$ reduction in SARS-CoV-2 RNA in the culture supernatant and $98 \%$ reduction in cell-associated viral RNA. Viral RNA reduction was approximately 5000-fold superior in the ivermectin-treated sample in comparison with the control sample, which indicates that ivermectin treatment resulted in an effective loss of viral material at 48 hours. Thus, ivermectin treatment can be implemented as currently 
LINES OF ATTACK IN COVID-19

Pharmacological treatment strategies at different points of SARS-COV-2 replication cycle

1a. Fusion
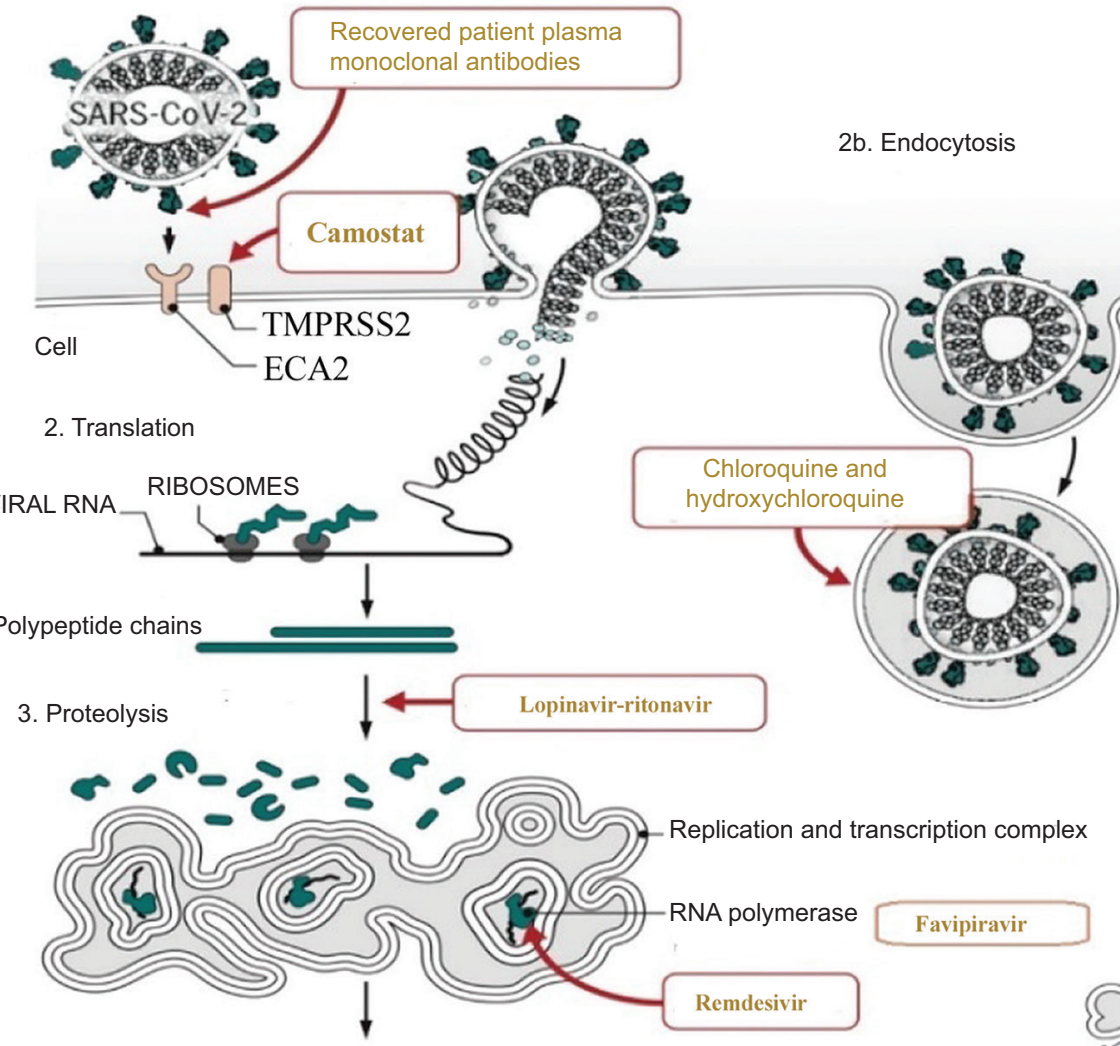

4. RNA translation and replication

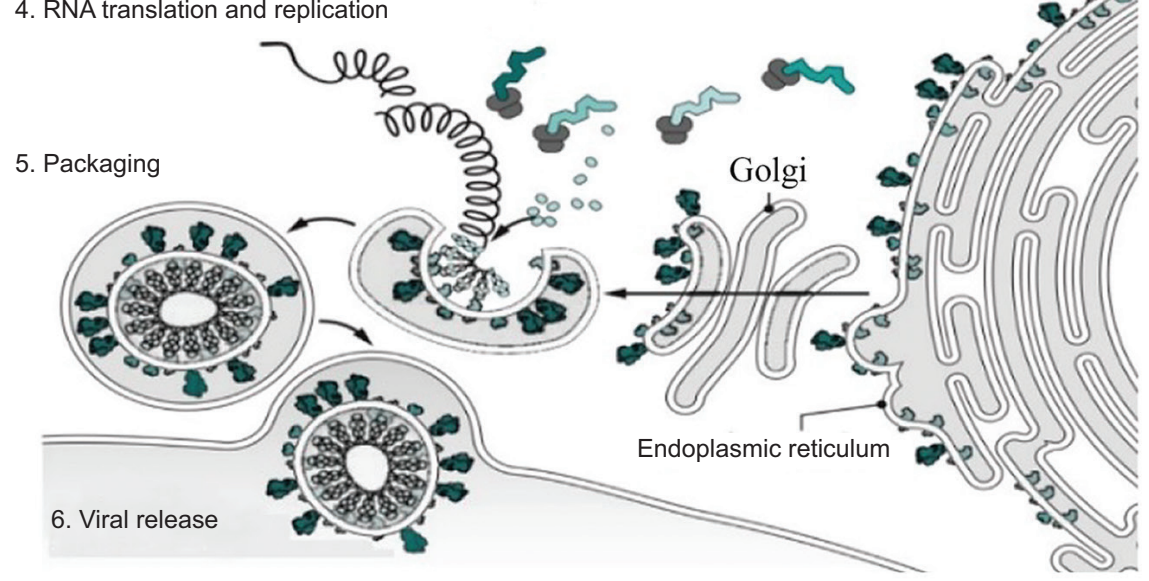

Figura 2. COVID-19 etiopathogenesis.

approved. ${ }^{14,15}$ The following ivermectin regimen (6-mg tablet presentation) is proposed depending on patient weight and disease severity: $15-20 \mathrm{~kg}, 3 \mathrm{mg} ; 21-40 \mathrm{~kg}$, $6 \mathrm{mg} ; 41-60 \mathrm{~kg}, 9 \mathrm{mg} ; 61-80 \mathrm{~kg}, 12 \mathrm{mg} ; 81-100 \mathrm{~kg}$,
$15 \mathrm{mg} ; 101-120 \mathrm{~kg}, 18 \mathrm{mg}$; in mild to moderate cases, for three days, and in severe cases, for six days.

Ivermectin side effects are scarce, and include abdominal pain, anorexia, diarrhea and nausea, but it is 
necessary to administer it with caution in patients receiving treatment with GABAergic psychotropic drugs and macrolides.

Anecdotal series refer to the use of antiretroviral drugs such as tenofovir and emtricitabine (which are used against human immunodeficiency virus to replace lopinavir/ritonavir) at conventional doses; the results have been promising, and, in the future, ivermectin availability, efficacy and tolerability should therefore be weighed.

Although the above proposals have been tested with varying degrees of success, the most effective long-term strategy is, recognizably, the development of vaccines that confer immunity. ${ }^{16,17}$ Prophylaxis in health personnel and contacts is not approved, although the use of ivermectine should be considered in the future owing to its availability, efficacy and tolerability.

\section{Patient recovery}

Cases under investigation where COVID-19 is ruled out will be guided by standard clinical criteria. In probable or confirmed COVID-19 cases, in addition to clinical criteria for recovery, respiratory tract samples negative results will have to be demonstrated in order for the patient to be released from isolation. This will require for two negative $P C R$ results to be obtained in two respiratory samples acquired at least 24 hours apart and after the patient no longer exhibits symptoms. Once the results are obtained, recovery will be established ${ }^{18,19}$ (Fig. 2).

Moreover, the priority critically-ill patients should be offered care with by age group has not been established, but it is considered important for the experience of the treating physician and the directives of the Bioethics Guidelines for Allocation of Limited Critical Medicine Resources in Emergency Situation, published by the General Health Council of Mexico, to prevail. ${ }^{20}$

\section{Conflicts of interest}

The authors declare that they have no conflicts of interest.

\section{Funding}

The authors did not receive any sponsoring to write this article.

\section{Ethical disclosures}

Protection of human and animal subjects. The authors declare no experiments were performed on humans or animals for this research.

Confidentiality of data. The authors declare that no patient data appear in this article.

Right to privacy and informed consent. The authors declare that no patient data appear in this article.

\section{References}

1. World Health Organization [website]. Switzerland: Report of the WHO-China joint mission on coronavirus disease 2019 (COVID19); 2020.

2. World Health Organization [website]. Switzerland: Global surveillance for human infection with novel coronavirus (2019-nCoV): interim guidance; 2020.

3. Wenzhong Liu, Hualan Li. COVID-19: Attacks the 1-beta chain of hemoglobin and captures the porphyrin to inhibit human heme metabolism. ChemRxiv. 2020 Jul 13; preprint.

4. Secretaría de Salud [website]. Mexico: Lineamiento estandarizado para la vigilancia epidemiológica y por laboratorio de COVID19; 2020.

5. Secretaría de Salud [website]. Mexico: Datos epidemiológicos; 2020.

6. Ministerio de Sanidad. Manejo clínico de pacientes con enfermedad por el nuevo coronavirus (COVID-19). España: Ministerio de Sanidad; 2020.

7. Chen H, Guo J, Wang C, Luo F, Yu X, Zhang W, et al. Clinical characteristics and intrauterine vertical transmission potential of COVID-19 infection in nine pregnant women: a retrospective review of medical records. Lancet. 2020;395(10226):809-815.

8. Centers for Disease Control and Prevention. Interim infection prevention and control recommendations for patients with confirmed 2019 novel coronavirus (2019-nCoV) or persons under investigation for 2019-nCoV in healthcare settings. USA; 2020.

9. Cao B, Wang Y, Wen D, Liu W, Wang J, Fan G, et al. A trial of lopinavir-ritonavir in adults hospitalized with severe Covid-19. N Engl J Med. 2020;7:1787-1799.

10. Kouznetsova V, Huang D, Tsigelny IF. Potential COVID-19 Protease inhibitors: repurposing: repurposing FDA approved drugs. ChemRxiv. 2020.

11. Wang Y, Zhang D, Du G, Du R, Zhao J, Jin Y, et al. Remdesivir in adults with severe COVID-19: a randomised, double-blind, placebo-controlled, multicentre trial. Lancet. 2020;395:1569-1578.

12. Holshue ML, DeBolt C, Lindquist S, Lofy KH, Wiesman J, Bruce H, et al. First case of 2019 novel coronavirus in the United States. N Engl J Med. 2020;382:929-936

13. Ni YN, Chen G, Sun J, Liang BM, Liang ZA. The effect of corticosteroids on mortality of patients with influenza pneumonia: a systematic review and meta-analysis. Crit Care. 2019;23:99.

14. Caly L, Druce JD, Catton MG, Jans DA, Wagstaff KM. The FDA-approved drug ivermectin inhibits the replication of SARS-CoV-2 in vitro. Antiviral Res. 2020;178:104787.

15. Smit MR, Ochomo E, Aljayyoussi G, Kwambai T, Abong'o B, Bayoh N. Efficacy and safety of high-dose ivermectin for reducing Malaria transmission (IVERMAL): protocol for a double-blind, randomized, placebo-controlled, dose-finding trial in Western Kenya. JMIR Res Protoc. 2016;17:e213.

16. Huang C, Wang Y, Li X, Ren L, Zhao J, Hu Y, et al. Clinical features of patients infected with 2019 novel coronavirus in Wuhan, China. Lancet. 2020;395:497-506

17. Sanders JM, Monogue ML, Jodlowski TZ, Cutrell JB. Pharmacologic treatments for coronavirus disease 2019 (COVID-19): a review. JAMA. 2020;323:1824-1836.

18. Guan WJ, Ni ZY, Hu Y, Liang WH, Ou CQ, He JX, et al. Clinical characteristics of coronavirus disease 2019 in China. $N$ Engl $J$ Med. 2020;382:1708-1720.

19. Shiraki K, Daikoku T. Favipiravir, an anti-influenza drug against life-threatening RNA virus infections. Pharmacol Ther. 2020;107512.

20. Consejo de Salubridad General. Guía Bioética para Asignación de Recursos Limitados de Medicina Crítica en Situación de Emergencia. Mexico: Consejo de Salubridad General; 2020. 